\title{
Competency based internship training programme in undergraduate dental education in Bangladesh: Clinical teachers and intern doctors' perception
}

\author{
Dr. Md. Immam Hossin', Prof. Dr. Mohammad Faruque ${ }^{2}$, Prof. Md. Humayun Kabir Talukder ${ }^{3}$, Dr. Md. Rasel Ahmad ${ }^{4}$ \\ Brig Gen (Dr) Md Abdullah Al Harun ${ }^{5}$ Brig Gen (Dr) Dipak Kumar Paul Chowdhury ${ }^{6}$
}

\begin{abstract}
Background: For the first 20 years or so after formal education in dentistry commenced at Glasgow in 1879, the manner of learning technical and clinical procedures was little different from what it had been since immemorial. In other words dental students learned by watching others until it was felt that they could be trusted to perform the procedure themselves. Rationale: The intern year is the first level of hands-on training in dentistry and is an essential step in every dental surgeon's career. Opportunity to apply, consolidate and expand one's clinical knowledge, skills and also progressively increase one's responsibility for providing safe, high-quality patient care. Opportunity to develop overall patient management skill especially for the general dental practitioner. The intern year should provide a balance between education, training and clinical responsibility, enabling interns to develop the professional and personal competencies that result in good patient care and provide a foundation for lifelong learning.
\end{abstract}

Objectives: The present study was undertaken to identify the Competency based internship training programme in undergraduate dental education in Bangladesh: Clinical teachers and intern doctors' perception

Methods: This descriptive type of cross sectional study was conducted in six public and private dental colleges of Bangladesh. A semi-structured questionnaire based on 5-point Likert scale was used to collect the clinical teachers and inter doctors' perceptions. The semi-structured questionnaire was prepared on the basis of logbook based internship training programme. Before administering the questionnaires to the respondents the investigator gave them an introductory idea about the purpose of the research.

Results: competencies acquired by the intern doctors were satisfactory but some problematic areas such as less duration of training period, no community placement, availability of training aid, lack of supervision as well as feedback etc were highlighted which interfered in achieving their satisfaction on their competencies.

Conclusion: To ensure excellence in all aspects of internship training programme, it can be concluded that intern doctors must need to acquire sufficient competencies in most of the clinical areas for their daily practice. There are many areas for further improvement through evaluating and developing the internship training programme as well as the logbook and strengthening the clinical environment in the institutes.

Key Words: Clinical teachers, Internship training, Dental education, logbook, intern doctors perception, Competencies.

\section{Introduction}

Competence assumes that all behaviors are performed with a degree of quality consistent with patient well-being and that

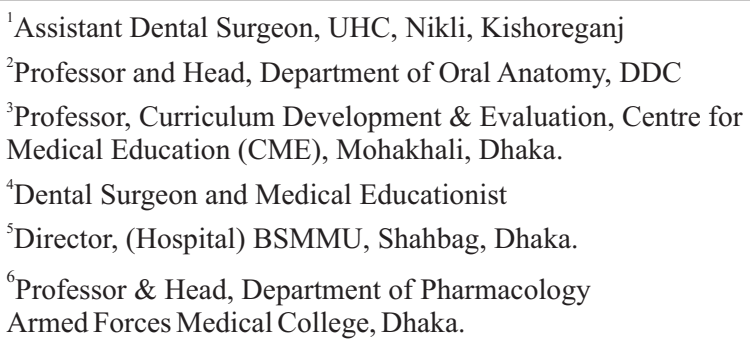

Address of correspondence: Dr. Md. Immam Hossin, BDS (DDC), MMEd (BSMMU), FICD (USA),

Assistant Dental Surgeon and Medical Educationist

UHC, Nikli, Kishoreganj

email: bulbulbds42@gmail.com the general dentist can self-evaluate treatment effectiveness. In competency-based dental education, what students learn is based upon clearly articulated competencies and further assumes that all behaviors/abilities are by foundation knowledge and psychomotor skills in biomedical, behavioral, ethical, clinical dental science, and informatics areas that are essential for independent and unsupervised performance as an entry-level general dentist. In creating curricula, dental faculty must consider the competencies to be developed through the educational process, the learning experiences that will lead to the development of these competencies, and ways to assess or measure the attainment of competencies ${ }^{1}$. Professional ethics in dentistry is one of the basic components for achieving success in dental practice because it ensures patients' confidence in adroitness of the practitioners as well as in the dental procedures to which they are subjected. The American Dental Association (ADA) defines dental ethics under five fundamental

Bangladesh Journal of Medical Education 2017;8(1):9-13. (C) 2017 Hossain et al., publisher and licensee Association for Medical Education. This is an Open Access article which permits unrestricted non-commercial use, provided the original work is properly cited. 
principles of the ADA Code that focuses patients` autonomy, non-maleficence, beneficence, justice and veracity ${ }^{2}$.

Assessment of interns' standard of care requires careful monitoring of their clinical performance and productivity. This is done as an integral part of dental education at King Saud University, College of Dentistry (KSU-CD), where the freshly graduate is required to undertake a twelve-month period as an intern before being fully registered as a licensed dentist ${ }^{3}$. Human oral cavity is a very good environment for the transmission, inoculation and growth of a variety of agents that can be infectious or detrimental to others. Hence, disease transmission can easily occur in dental clinics through various routes. These include direct contact with blood, oral fluids, or other secretions; indirect contact with contaminated instruments, operatory equipment, or environmental surfaces; or contact with contaminants that are airborne. In dental practice, dentists frequently encounter patient blood and blood-contaminated saliva during dental procedures which make transmission greatest from patient to dentist. This is the reason why infection control rules an integral part in dental practice ${ }^{4}$. The dental interns are recent graduate students who must finish a oneyear internship program. The program included a clinical training where they performed a complete comprehensive dental treatment to patients including root canal therapy and operative dentistry. Their daily clinical practice is usually based on what they have been learned during their undergraduate study. So, at this stage of training, it was interesting to know their idea about their current and future attitudes toward rubber dam usage. Therefore, the aim of this study was to evaluate the attitudes of using rubber dam by the dental interns in college of Dentistry of Riyadh Dental Colleges ${ }^{5}$. The intern year should provide a balance between education, training and clinical responsibility, enabling interns to develop the professional and personal competencies that result in good patient care and provide a foundation for lifelong learning. In Bangladesh internship training programme was voluntary but in the year of 2007 Bangladesh medical and dental council make it mandatory for all the dental graduates ${ }^{6}$.

\section{Methodology}

This descriptive type of cross sectional study was conducted in six public and private dental colleges of Bangladesh after getting written permission from the principal of the respective dental colleges. Voluntary participation of the intern doctors was ensured and the names of the intern doctors as well as clinical teachers were kept confidential. The clinical teachers and intern doctors from the different dental colleges were the study population; among them two hundred (200) intern doctors and forty clinical teachers (40) were taken as sample by convenient sampling. Data collection instrument was a semi-structured questionnaire with 5-point Likert scale with maximum score 5 and minimum score 1 . The instruments were pretested in Rajshahi medical college dental unit. The researcher himself visited selected dental colleges. He was introduced himself to the principal of the dental colleges and the teachers of all the clinical departments to conduct the study. Specific time was taken from the clinical teachers and to brief the intern doctors about the purpose and benefit of the study. The intern doctors were briefed about the questionnaire. The investigator himself collected all the data with prior permission of the principles and heads of the concerned departments. The semi-structured questionnaire was prepared on the basis of logbook based internship training programme. Before administering the questionnaires to the respondents the investigator gave them an introductory idea about the purpose of the research. All the collected data were checked manually. Data entry, editing, processing and analysis have been done by using 19 version of SPSS compute software programme. Interpretations were done subsequently. Data were presented by tables and graphs with necessary description where necessary for easy understanding and interpretation. Name of the colleges, teachers, students were not being disclosed. Findings of the study were used only for research purpose.

\section{Results}

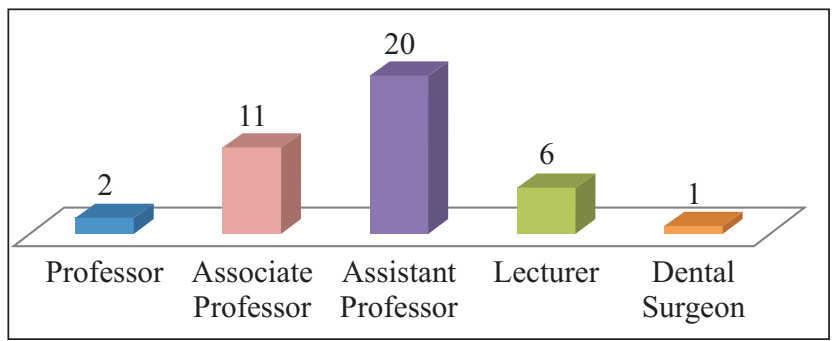

show out of 40 teachers' majority 20(50) were Assistant Professor, 11 (27.5) were Associate Professor, 2(5) were Professor, 6(15) were lecturer and 1(2.5) were dental surgeon. Table 1 shows out of 40 teachers majority 14(35) from Conservative dentistry, 11(27.5) from Oral \& Maxillofacial Surgery, 7(17.5) from prosthodontics, 5(12.5) from Periodontology, 2(5) from Children dentistry and 1(2.5) from Orthodontic department.

Table 1: Distribution of the teachers by their department $(\mathrm{n}=40)$

\begin{tabular}{|l|c|c|c|}
\hline $\begin{array}{l}\text { Duration of training } \\
\text { for the intern doctors } \\
\text { in individual subject }\end{array}$ & Frequency & Percent (\%) & Mean \\
\hline Prosthodontics & 6 & 16.67 & 12 Weeks \\
\hline Children dentistry & 2 & 5.56 & 11 Weeks \\
\hline $\begin{array}{l}\text { Oral \& Maxillofacial } \\
\text { Surgery }\end{array}$ & 10 & 27.78 & 13 Weeks \\
\hline Periodontology & 5 & 13.89 & 10 Weeks \\
\hline Orthodontics & 1 & 2.78 & 12 Weeks \\
\hline Conservative dentistry & 12 & 33.33 & 14 Weeks \\
\hline Total & 36 & 100.0 & \\
\hline
\end{tabular}


Table 2 shows different level of core competencies, out of 200 intern doctors majority 164(82) mentioned satisfied, $36(18)$ were very satisfied in scope of proper history taking and recording.190(95) mentioned very satisfied in scope of proposing investigation to the patients. 181(90.5) mentioned that they were satisfied in scope of making diagnosis. 111(55.5) mentioned satisfied and 59(29.5) were dissatisfied in dealing with dental emergencies e.g. (faint, syncope, acute hypoglycemia etc. 162(81) mentioned that they were satisfied and 22(11) mentioned dissatisfied in scope of performing local anaesthesia. 130(66) mentioned satisfied,19(9.6) were neither satisfied nor dissatisfied, 45(22.8) were dissatisfied in satisfaction about the competencies acquiring.

Table 2: Distribution of the intern doctors by their opinion about the statements in relation to competencies

\begin{tabular}{|c|c|c|c|c|c|c|}
\hline \multirow[t]{2}{*}{ Statements in relation to the competencies } & \multicolumn{5}{|c|}{ Frequency $(\%)$} & \multirow[t]{2}{*}{ Total } \\
\hline & VD & D & NSND & $\mathbf{S}$ & VS & \\
\hline Scope of proper history taking and recording & - & - & - & $164(82)$ & $36(18)$ & 200 \\
\hline Scope of proposing investigations to the patients & - & - & $1(.5)$ & 190(95) & $9(4.5)$ & 200 \\
\hline Scope of counselling the patient and or attendants & - & $2(1.0)$ & $10(5)$ & $183(91.5)$ & $5(2.5)$ & 200 \\
\hline Scope of making diagnosis & - & $4(2)$ & $10(5)$ & $181(90.5)$ & $5(2.5)$ & 200 \\
\hline Scope of writing prescriptions & - & $3(1.5)$ & $4(2)$ & $182(91.5)$ & $10(5)$ & 200 \\
\hline $\begin{array}{l}\text { Dealing with dental emergencies e.g. (faint, syncope, acute } \\
\text { hypoglycemia etc.) }\end{array}$ & $10(5)$ & $59(29.5)$ & $14(7)$ & $111(55.5)$ & $6(3)$ & 200 \\
\hline $\begin{array}{l}\text { Scope of interpretation of investigations and records (e.g. X-ray, } \\
\text { OPG finding etc.) }\end{array}$ & $2(1)$ & 94(47) & $21(10.5)$ & $81(40.5)$ & $2(1)$ & 200 \\
\hline Scope of performing local anaesthesia & - & $22(11)$ & $10(5)$ & $162(81)$ & $6(3)$ & 200 \\
\hline Scope of intraoral examination & $1(.5)$ & $6(3)$ & $12(6)$ & $178(89)$ & $3(1.5)$ & 200 \\
\hline Scope of relevant discussion with the supervisors & $2(1)$ & $36(18.1)$ & $29(14.6)$ & $131(65.8)$ & $1(.5)$ & 199 \\
\hline Satisfaction about the competencies acquiring & $2(1)$ & $45(22.8)$ & $19(9.6)$ & $130(66)$ & $1(.5)$ & 197 \\
\hline
\end{tabular}

$\mathbf{V D}=$ Very dissatisfied, $\mathbf{D}=$ Dissatisfied, $\mathbf{N S N D}=$ neither satisfied nor dissatisfied, $\mathbf{S}=$ Satisfied, $\mathbf{V S}=$ Very satisfied)

Table 3 shows out of 200 intern doctors most of them 166(83) mentioned satisfied in performing of scaling, 168(84) mention were satisfied in performing of operculectomy and 161(80.9) mentioned satisfied in performing periodontal pocket curettage. Most of them 180(90) mentioned were satisfied in performing pulpotomy and 166(83) mentioned were satisfied in performing of pulpectomy. Majority 156(78) mentioned satisfied and 42(21) were very satisfied in performing deciduous tooth restoration. About 145(72.5) mentioned satisfied, 52(26) were very satisfied in performing deciduous tooth extraction. Majority 139(69.5) mentioned satisfied in constructing partial denture. Majority 95(47.7) mentioned dissatisfied, 73(36.7) were satisfied in constructing removable appliance. Majority 90(45) mentioned dissatisfied in treatment of different malocclusions using removable appliance. Majority 104(52) mentioned satisfied and 5(2.5) were very satisfied in preparing class 1 , class 2 , class 3, class 4 and class 5 cavities. Majority 137(68.5) mentioned satisfied in performing root canal treatment (RCT) of anterior and posterior teeth. Majority 83(41.5) mentioned satisfied, 60(30) were dissatisfied and 8(4) were very dissatisfied in performing minor surgery cysts, tumors, apisectomy. 
Table 3: Distribution of the intern doctors by their opinion regarding the environment to ensure adequate patient service and as well as optimum training of the intern doctors

\begin{tabular}{|c|c|c|c|c|c|c|}
\hline \multirow[b]{2}{*}{ Statement in relation to clinical competencies } & \multicolumn{5}{|c|}{ Frequency No (\%) } & \multirow[b]{2}{*}{ Total } \\
\hline & $\begin{array}{l}\text { VD } \\
(1)\end{array}$ & $\begin{array}{c}\mathrm{D} \\
(2)\end{array}$ & $\begin{array}{c}\text { NSND } \\
\text { (3) }\end{array}$ & $\begin{array}{c}S \\
(4)\end{array}$ & $\begin{array}{l}\text { VS } \\
(5)\end{array}$ & \\
\hline Performing scaling & - & $1(.5)$ & $1(.5)$ & $166(83)$ & $32(16)$ & 200 \\
\hline Performing operculectomy & $1(.5)$ & - & - & $168(84)$ & $31(15.5)$ & 200 \\
\hline Performing gingivectomy & $1(.5)$ & $2(1)$ & $1(.5)$ & $177(88.5)$ & $19(9.5)$ & 200 \\
\hline Performing periodontal pocket curettage & - & $21(10.6)$ & $4(2)$ & $161(80.9)$ & $13(6.5)$ & 199 \\
\hline Performing pulpotomy & - & $1(.5)$ & $18(9)$ & $180(90)$ & $1(.5)$ & 200 \\
\hline Performing pulpectomy & - & $1(.5)$ & $1(.5)$ & $166(83)$ & $32(16)$ & 200 \\
\hline Performing deciduous tooth restoration & $1(.5)$ & - & $1(.5)$ & $156(78)$ & $42(21)$ & 200 \\
\hline Performing deciduous tooth extraction & - & $2(1)$ & $1(.5)$ & $145(72.5)$ & $52(26)$ & 200 \\
\hline Taking impression & $1(.5)$ & - & $9(4.5)$ & $159(79.5)$ & $31(15.5)$ & 200 \\
\hline Constructing partial denture & $1(.5)$ & $25(12.5)$ & $11(5.5)$ & $139(69.5)$ & $24(12)$ & 200 \\
\hline Constructing complete denture & - & $119(59.5)$ & $26(13.1)$ & $48(24.1)$ & $6(3)$ & 199 \\
\hline Preparing tooth for metal ceramic crown & $2(1)$ & $132(66)$ & $8(4)$ & $57(28.5)$ & $1(.5)$ & 200 \\
\hline Constructing removable appliance & - & $95(47.7)$ & $30(15.1)$ & $73(36.7)$ & $1(.5)$ & 199 \\
\hline Orthodontic diagnosis and treatment planning & - & $83(41.5)$ & $31(15.5)$ & $86(43)$ & - & 200 \\
\hline $\begin{array}{l}\text { Treatment of different malocclusions using removable } \\
\text { appliance }\end{array}$ & $2(1)$ & $90(45)$ & $38(19)$ & $70(35)$ & - & 200 \\
\hline Preparing class 1 , class 2 , class 3 , class 4 and class 5 cavities & $1(.5)$ & $53(26.5)$ & $37(18.5)$ & $104(52)$ & $5(2.5)$ & 200 \\
\hline Restoring class 1 , class 2 , class 3 , class 4 and class 5 cavities & - & $51(25.5)$ & $35(17.5)$ & $109(54.5)$ & $5(2.5)$ & 200 \\
\hline $\begin{array}{l}\text { Performing root canal treatment }(\mathrm{RCT}) \text { of anterior and } \\
\text { posterior teeth }\end{array}$ & $1(.5)$ & $\begin{array}{c}39(19.5) \\
28\end{array}$ & $\begin{array}{l}3(1.5) \\
14 \quad 20\end{array}$ & $137(68.5)$ & $20(10)$ & 200 \\
\hline Performing extraction of anterior and posterior teeth & $1(.5)$ & $42(21)$ & $7(3.5)$ & $129(64.5)$ & $21(10.5)$ & 200 \\
\hline Performing minor surgery, cyst, tumors, apisectomy etc. & $8(4)$ & $60(30)$ & $42(21)$ & $83(41.5)$ & $7(3.5)$ & 200 \\
\hline
\end{tabular}

(VD=Very dissatisfied, $\mathbf{D}=$ =Dissatisfied, $\mathbf{N S N D}=$ neither satisfied nor dissatisfied, $\mathbf{S}=$ Satisfied, $\mathbf{V S}=$ Very satisfied)

\section{Discussion}

In this study shows different level of core competencies, out of 200 intern doctors majority 164(82) mentioned satisfied, 36(18) were very satisfied in scope of proper history taking and recording.190 (95) mentioned very satisfied in scope of proposing investigation to the patients. 181(90.5) mentioned that they were satisfied in scope of making diagnosis. 111(55.5) mentioned satisfied and 59(29.5) were dissatisfied in dealing with dental emergencies e.g. (faint, syncope, acute hypoglycemia etc. 162(81) mentioned that they were satisfied and 22(11) mentioned dissatisfied in scope of performing local anesthesia. 130(66) mentioned satisfied, 19(9.6) were neither satisfied nor dissatisfied, 45(22.8) were dissatisfied in satisfaction about the competencies acquiring. Out of 200 intern doctors most of them 166(83) mentioned satisfied in performing of scaling, 168(84) mention were satisfied in performing of operculectomy and 161(80.9) mentioned satisfied in performing periodontal pocket curettage. Most of them 180(90) mentioned were satisfied in performing pulpotomy and 166(83) mentioned were satisfied in performing of pulpectomy. Majority 156(78) mentioned satisfied and 42(21) were very satisfied in performing deciduous tooth restoration. About 145(72.5) mentioned satisfied, 52(26) were very satisfied in performing deciduous tooth extraction. Majority 139(69.5) mentioned satisfied in constructing partial denture. Majority 95(47.7) mentioned dissatisfied, 73(36.7) were satisfied in constructing removable appliance. Majority 90(45) mentioned dissatisfied in treatment of different malocclusions using removable appliance. Majority 104(52) mentioned satisfied and 5(2.5) were very satisfied in preparing class 1 , class 2 , class 3 , class 4 and class 5 cavities. Majority 137(68.5) mentioned satisfied in performing root canal treatment (RCT) of anterior and posterior teeth. Majority 83(41.5) mentioned satisfied, 60(30) were dissatisfied and 8(4) were very dissatisfied in performing minor surgery cysts, tumors, apisectomy. A study conducted by Anjum et al.(2014) ${ }^{7}$ showed that 227 interns participated, of which $25.1 \%$ were males and $74.9 \%$ females. $52.4 \%$ followed the six steps involved in rational prescription process, whenever they prescribed medicines. 
A study conducted by Fazel, et al $(2008)^{8}$ in which that out of 300 questionnaires distributed in the 30 provinces of the country, 250 questionnaires $(83 \%)$ were returned. While most of the participants considered the competencies as necessary for an Iranian dentist, less than $40 \%$ of the respondents believed that the graduates acquire the most required competencies of the profession during the current educational program. A study conducted by Licari et. al. (2008) ${ }^{9}$ in which Fewer than half (46 percent) of the respondents were able to identify the conventional definition of competency that was stated as "a set of skills, knowledge, and values that characterize beginning dentists." Almost a quarter each identified "competency" as a type of clinical examination format ( 26 percent) or roughly the same as a clinical discipline ( 25 percent). Nine percent associated the primary meaning of "competency" as an accreditation requirement. A study conducted by Gerrow et. al. $(2006)^{10}$.The survey asked participants to supply demographic information and rate each of the forty-six competencies on a 5-point Likert scale. The response rate was 43.1 percent ( 315 total usable responses). Self-reported demographic data was used to create respondent subgroups. The participants rated all of the competencies quite high with thirty-six of the forty-six receiving rankings averaging 4.0 or higher on the 5-point scale. No competency received a ranking averaging lower than 3.0. A study conducted by Willis et. al. (2009) ${ }^{11}$. The ADEA Competencies for the New General Dentist contain a significant number of practice management-related competencies. To date, these have been taught primarily in a lecture format in the third and fourth years of the dental curriculum. Presenting information in this way only satisfies the lower level learning skills, not the skills needed to become a competent general dentist.

\section{Conclusion}

The general dentist must have a broad biomedical and clinical education and be able to demonstrate professional and ethical behavior as well as effective communication and interpersonal skills. In addition, he or she must have the ability to evaluate and utilize emerging technologies, continuing professional development opportunities, and problem-solving and critical thinking skills to effectively address current and future issues in health care.

\section{References}

1. ADEA Competencies for the New General Dentist, (2011); Journal of Dent Education; Vol. 75, No.7, pp.932-935.

2. Al-Zahin SA,Al-Sadhan SAR, Ahmedani MS, (2014), Penception of BDS Students and fresh graduates about significence of profensional etics in dentistry, J Pak Med Assoc, Vol. 64, no. 2, PP. 118-123.

3. Sadig W,(2004), An assessment of clinical productivity of dental interns at king saud university, Pakistan Oral and Dental Journal, vol.27, no.1, pp.107-112.

4. Alshiddi IF, (2015), Attitude and awareness of dental students and interns toward infection control measures in prosthodontic clinics, Eur J Dent,vol.7,no.2,pp.1519.

5. Al-Abdulwahhab BM,Al-Thabit $\mathrm{H}, \mathrm{Al}$-Harthi A, AlAshagi A, Al-Qabbani F, Al-Ghamdi S, Al-Taher R, (2012), The attitudes of dental interns to the use of the rubber dam at Riyadh Dental College, Saudi Endod J, vol.2, no.1 pp.75-79.

6. Internship logbook by BM\&DC (2007)

7. Anjum M, Parthasanathi P, Monica M, Yadav K, Irram A, Keerthi T, Kistigari P, (2014), Evaluating the knowledge of interns in preseribing basic drugs used in dentistry - Across sectional study, wedmed central> orginal Articles, pp.3-11.

8. Fazel A, Jafari A, Khami MR, et al. 2001, 'Dental Curriculum Revision in Iran: Dentists' Perspective on Achievement of Essential Competencies through National Curriculum', Beheshti Univ Dent J. Vol.18, No.4, pp. 140.

9. Frank W. Licari, D.D.S.; David W. Chambers, Ed.M., M.B.A., Ph.D. "Some Paradoxes in Competency-Based Dental Education" Journal of Dental Education, Vol.72, Num.1, pp-1-18.

10 Jack D. Gerrow, D.D.S., M.S., M.Ed.; H. Joseph Murphy, Ed.D.; Marcia A. Boyd, D.D.S., M.A., L.H.D. (Hon). "Competencies for the Beginning Dental Practitioner in Canada: A Validity Survey" Journal of Dental Education. Vol.70, Num.10, pp.1076-1080.

11. David O. Willis, D.M.D., M.B.A., C.F.P. "Using Competencies to Improve Dental Practice Management Education". Journal of Dental Education. Vol.73, Num.10, pp-1144-1152. 